\title{
Genetic polymorphisms in HIF1A are associated with prostate cancer risk in a Chinese population
}

\author{
$\mathrm{Pu} \mathrm{Li}^{1, *}$, Qiang Cao ${ }^{1, *}$, Peng-Fei Shao ${ }^{1}$, Hong-Zhou Cai ${ }^{1}$, Hai Zhou ${ }^{1}$, Jia-Wei Chen ${ }^{1}$, Chao Qin ${ }^{1}$, \\ Zheng-Dong Zhang ${ }^{2}$, Xiao-Bing Ju${ }^{1}$ and Chang-Jun Yin ${ }^{1}$
}

The hypoxia-inducible factor-1 $\alpha$ (HIF-1 $\alpha$ ) plays an important role in regulating angiogenesis, which is essential for tumor growth and metastasis. Genetic variations of HIF1A (coding HIF-1 $\alpha$ ) have been shown to influence an individual's susceptibility to many human tumors; however, evidence on associations between HIF1A single-nucleotide polymorphisms (SNPs) and prostate cancer (PCa) risk is conflicting. We genotyped three potentially functional polymorphisms in HIF1A (rs11549465, rs11549467 and rs2057482) using the TaqMan method and assessed their associations with PCa risk in a case-control study of 662 PCa patients and 716 controls in a Chinese Han population. Compared with rs 11549467 GG genotype, the variant genotypes GA+AA had a significantly increased PCa risk (adjusted odds ratio $(O R)=1.70 ; 95 \%$ confidence interval $(\mathrm{Cl})=1.06-2.72)$, particularly among older patients $(\mathrm{OR}=2.01$; $95 \% \mathrm{Cl}=1.05-3.86)$, smokers $(\mathrm{OR}=2.06 ; 95 \% \mathrm{Cl}=1.07-3.99)$, never drinkers $(\mathrm{OR}=2.16 ; 95 \% \mathrm{Cl}=1.20-3.86)$ and patients without a family history of cancer $(\mathrm{OR}=1.71 ; 95 \% \mathrm{Cl}=1.02-2.89)$. Furthermore, patients with rs 11549467 variant genotypes were associated with a higher Gleason score $(O R=2.14 ; 95 \% \mathrm{Cl}=1.22-3.75)$. No altered PCa risk was associated with the rs 11549465 and rs2057482 polymorphism. However, the combined variant genotypes of rs2057482 and rs 11549467 were associated with increased $\mathrm{PCa}$ risk (OR=2.10; $95 \% \mathrm{Cl}=1.23-3.57$ among subjects carrying three or more risk alleles). These results suggest that $H I F 1 A$ polymorphisms may impact PCa susceptibility and progression in the Chinese Han population.

Asian Journal of Andrology (2012) 14, 864-869; doi:10.1038/aja.2012.101; published online 8 October 2012

Keywords: genetic association; HIF-1 $\alpha$; HIF1A; polymorphism; prostate cancer

\section{INTRODUCTION}

Prostate cancer (PCa) is the most commonly diagnosed cancer in Western males and ranks second only to lung cancer in cancer mortality. ${ }^{1} \mathrm{PCa}$ incidence is significantly lower in Asian males; however, in China, as lifestyles are becoming more Westernized, the incidence rate of $\mathrm{PCa}$ has increased significantly in recent years to $1.6 / 100000$ per year, ranking one hundred and seventieth in the world. ${ }^{2}$ Epidemiological studies have showed that age, smoking, environmental factors, racial backgrounds and a family history of PCa are associated with PCa. However, only a few exposed individuals develop PCa in their lifetime, which suggests that genetic susceptibility may also be involved in the etiology of PCa. ${ }^{3}$ Recent studies suggest that genetic polymorphisms of genes involved in prostate angiogenesis may confer susceptibility to PCa. ${ }^{4-6}$

Angiogenesis is essential for tumor development and metastasis, and in various types of tumors, including urological malignancies, it has been reported that angiogenesis was closely associated with advanced disease status and poor prognosis. ${ }^{7,8}$ The hypoxia-inducible factor-1 (HIF-1) plays an important role in regulating angiogenesis, cell adhesion, metastatic spread and apoptosis. ${ }^{9}$ HIF-1 is a heterodimeric transcription factor consisting of $\alpha$ and $\beta$ subunits, of which HIF- $1 \alpha$ is the oxygen-regulated factor that determines HIF- 1 activity. ${ }^{10}$
Overexpression of HIF- $1 \alpha$ has been observed in most solid tumors. ${ }^{7}$ As for PCa, it has been suggested that HIF- $1 \alpha$ is overexpressed even in early-stage PCa and increases transcription of vascular endothelial growth factor. ${ }^{11}$

Two single-nucleotide polymorphisms (SNPs) in HIF1A which result in proline to serine (rs11549465) and alanine to threonine (rs1 1549467) amino acid substitutions, respectively, were found within the Nterminal activation domain of HIF-1 $\alpha^{12}$ In head and neck squamous cell carcinoma, Tanimoto et al..$^{13}$ found that variants of these two polymorphisms significantly enhanced transcription activities and these polymorphic variants were associated with higher disease stage. After that, a large body of association studies investigated the role of these two polymorphisms in various types of cancer, ${ }^{14}$ including breast cancer, ${ }^{15,16}$ oral cancer, ${ }^{17,18}$ renal cell cancer, ${ }^{19}$ colorectal cancer, ${ }^{20,21}$ hepatocellular carcinoma, ${ }^{22} \mathrm{PCa}^{4,23-25}$ and lung cancer. ${ }^{26}$ For PCa, Chau et al. ${ }^{25}$ reported that rs 11549465 polymorphism conferred susceptibility to androgen-independent $\mathrm{PCa}$ and contributed to the progression or metastasis of this disease, whereas no association between those two polymorphisms and PCa risk was reported by a large case-control cohort study. ${ }^{24}$ Recently, Foley et al. ${ }^{23}$ reported rs11549465 SNP associated with susceptibility to clinically localized PCa but not with elevated expression of hypoxic biomarkers. 
To the best of our knowledge, no reports have been published regarding the role of HIF1A polymorphism in PCa in Chinese populations. Therefore, the present study was designed to investigate the association between HIF1A polymorphism and risk of PCa in our ongoing hospital-based case-control study in a Chinese Han population. In addition to rs11549465 and rs11549467 SNPs, we also tried to select other potential functional polymorphisms in HIF1A according to the following criteria: (1) located in the $5^{\prime}$-flanking regions, $5^{\prime}$ untranslated region (UTR), 3' UTR and coding regions with amino acid changes; and (2) minor allele frequency $>5 \%$ in Chinese population. According to the criteria, another SNP (rs2057482), which is located in the $3^{\prime}$ UTR region of HIF1A, was also investigated.

\section{MATERIALS AND METHODS}

\section{Study subjects}

The study was approved by the Institutional Review Board of Nanjing Medical University. In total, 662 pathologically confirmed PCa patients and a group of 716 age-matched controls were enrolled in this study. The controls were cancer-free people who were seeking physical examination in the outpatient departments at the hospital. All subjects were genetically unrelated ethnic Han Chinese recruited in an ongoing study starting in September 2003 at The First Affiliated Hospital of Nanjing Medical University, Nanjing, China. Before recruitment, all subjects were interviewed in person to collect demographic data and exposure information, including age, race, tobacco use, alcohol use and family history of cancer. Those who smoked daily for more than 1 year were defined as ever smokers, and the other were considered as never smokers. Individuals who drank at least three times per week for a period lasting more than 6 months were defined as ever drinkers and the rest were considered as never drinkers. Disease was classified according to the World Health Organization criteria and the stage was divided into localized and advanced cancer based on the tumor-node metastasis classification system promulgated by the American Joint Committee on Cancer. Pathological grade was recorded as the Gleason score according to the 2005 International Society of Urological Pathology consensus conference ${ }^{27}$ on Gleason grading of prostatic carcinoma. After completion of the interview, about $5 \mathrm{ml}$ venous blood samples were obtained from the patients and controls after written informed consent was obtained.

\section{Genotyping}

The genotyping of the three HIF1A polymorphisms (rs11549465, rs11549467 and rs2057482) was performed using TaqMan SNP Genotyping Assays (Applied Biosystems, Foster City, CA, USA). The sequences of primer and probe for each SNP are available on request. Amplification was performed under the following conditions: $50^{\circ} \mathrm{C}$ for $2 \mathrm{~min}, 95^{\circ} \mathrm{C}$ for $10 \mathrm{~min}$ followed by 45 cycles of $95^{\circ} \mathrm{C}$ for $15 \mathrm{~s}$ and $60^{\circ} \mathrm{C}$ for $1 \mathrm{~min}$. According to the manufacturer's instructions, amplifications and analysis were performed in the 384-well ABI 7900HT Real Time PCR System (Applied Biosystems) and the SDS 2.3 software were used for allelic discrimination (Applied Biosystems). Four negative controls were included in each plate to ensure accuracy of the genotyping. The success rate for genotyping of the polymorphism is $100 \%$. About $10 \%$ of the samples were randomly selected for repeated genotyping for confirmation, and the results were $100 \%$ concordant.

\section{Statistical analyses}

The differences in the distributions of demographic characteristics, selected variables and frequencies of genotypes between cases and controls were evaluated using the unpaired $t$-test (for continuous variables) or $\chi^{2}$ test (for categorical variables). SNP allele frequencies were tested against departure from Hardy-Weinberg equilibrium using a goodness-of-fit $\chi^{2}$ test before analysis. The associations between HIF1A polymorphisms and PCa risk were estimated by computing odds ratios (ORs) and $95 \%$ confidence intervals (CIs) from unconditional logistic regression analysis with the adjustment for age, smoking status, drinking status and family history of cancer. All analyses were performed with the software SAS 9.1.3 (SAS Institute, Cary, NC, USA) with two-sided $P$ values and $P<0.05$ was considered statistically significant. Power and Sample Size Calculation software(PS $3.0)^{28}$ was used to calculate the power of the study.

\section{RESULTS}

\section{Characteristics of the study population}

The frequency distributions of selected characteristics of the cases and controls are shown in Table 1. There was no significant difference between the cases and controls in age $(P=0.829)$; however, there were more smokers and drinkers among the cases than the controls $(P<0.001$ and $P=0.042$, respectively). In addition, the frequency of first-degree relatives with cancer was higher in the cases than in controls $(25.5 \%$ vs. $15.2 \% ; P<0.001)$.

Table 1 Frequency distribution of selected variables of the PCa cases and controls

\begin{tabular}{|c|c|c|c|c|c|}
\hline \multirow{2}{*}{ Variables } & \multicolumn{2}{|c|}{ Cases $(n=662)$} & \multicolumn{2}{|c|}{ Controls $(\mathrm{n}=716)$} & \multirow{2}{*}{$P^{a}$} \\
\hline & $\mathrm{n}$ & $\%$ & $n$ & $\%$ & \\
\hline $\begin{array}{l}\text { Age (year) } \\
\quad(\text { mean } \pm \text { s.d.) }\end{array}$ & \multicolumn{2}{|c|}{$71.5 \pm 8.0$} & \multicolumn{2}{|c|}{$71.5 \pm 7.0$} & 0.829 \\
\hline$\leqslant 71$ & 308 & 46.5 & 360 & 50.3 & 0.164 \\
\hline$>71$ & 354 & 53.5 & 356 & 49.7 & \\
\hline \multicolumn{6}{|l|}{ Smoking status } \\
\hline Never & 277 & 41.8 & 350 & 48.9 & 0.009 \\
\hline Ever & 385 & 58.2 & 366 & 51.1 & \\
\hline \multicolumn{6}{|l|}{$\begin{array}{l}\text { Pack-years of } \\
\text { smoking }\end{array}$} \\
\hline 0 & 277 & 41.8 & 350 & 48.9 & $<0.001$ \\
\hline $0-32$ & 153 & 23.1 & 181 & 25.3 & \\
\hline$>32$ & 232 & 35.1 & 185 & 25.8 & \\
\hline \multicolumn{6}{|l|}{ Drinking status } \\
\hline No & 468 & 70.7 & 541 & 75.6 & 0.042 \\
\hline Yes & 194 & 29.3 & 175 & 24.4 & \\
\hline \multicolumn{6}{|l|}{$\begin{array}{l}\text { Family history of } \\
\text { cancer }\end{array}$} \\
\hline No & 493 & 74.5 & 607 & 84.8 & $<0.001$ \\
\hline Yes & 169 & 25.5 & 109 & 15.2 & \\
\hline \multicolumn{6}{|l|}{ Clinical stage } \\
\hline Localized & 529 & 79.9 & & & \\
\hline Advanced & 133 & 20.1 & & & \\
\hline \multicolumn{6}{|l|}{ Gleason score } \\
\hline$<7$ & 230 & 34.7 & & & \\
\hline$=7$ & 219 & 33.1 & & & \\
\hline$>7$ & 213 & 32.2 & & & \\
\hline \multicolumn{6}{|l|}{ PSA (ng ml ${ }^{-1}$ ) } \\
\hline$\leqslant 20$ & 294 & 44.4 & & & \\
\hline$>20$ & 368 & 55.6 & & & \\
\hline
\end{tabular}

Abbreviations: PCa, prostate cancer; PSA, prostate-specific antigen.

${ }^{a} t$-test for age distributions between the cases and controls; two-sided $\chi^{2}$ test for others selected variables between the cases and controls. 
Association between HIF1A polymorphisms and risk of PCa

Allele frequencies and genotype distributions of HIF1A (rs11549465, rs11549467 and rs2057482) polymorphisms are shown in Table 2. All observed genotype frequencies in controls conformed to HardyWeinberg equilibrium $(P=0.267, \quad P=0.554$ and $P=0.10$ for rs11549465, rs11549467 and rs2057482, respectively). The distributions of rs11549465 and rs2057482 polymorphisms were not significantly different between cases and controls $(P=0.302$ and $P=0.258$, respectively). However, the genotype frequencies for rs11549467 polymorphism between the cases and controls were significantly different $(P=0.048)$, especially in the dominant model for the rs11549467 A allele $(P=0.020)$. When using the most common genotype (rs11549467 GG) as the reference, we found that the rare genotypes (GA+AA) were associated with a statistically significantly increased risk of $\mathrm{PCa}$ (adjusted $\mathrm{OR}=1.70 ; 95 \% \mathrm{CI}=1.06-2.72$ ). The allele frequencies of rs11549465, rs11549467 and rs2057482 in controls were similar with the allele frequencies in the HapMap database $(0.04,0.02$ and 0.23 in our controls, respectively; $0.047,0.056$ and 0.244 in the HapMap database, respectively).

\section{Stratified analysis of rs11549467 polymorphism and risk of PCa}

We then evaluated the effect of the rs 11549467 polymorphism on PCa risk stratified by age, smoking status, drinking status and family history of cancer. As shown in Table 3, the association between rs11549467 GA+AA genotypes and PCa risk appeared stronger in subgroups of older subjects (adjusted $\mathrm{OR}=2.01 ; 95 \% \mathrm{CI}=$ 1.05-3.86), smokers (adjusted $\mathrm{OR}=2.06 ; 95 \% \mathrm{CI}=1.07-3.99$ ), never drinkers (adjusted $\mathrm{OR}=2.16 ; 95 \% \mathrm{CI}=1.20-3.86$ ) and individuals without family history of cancer (adjusted $\mathrm{OR}=1.71$; 95\%CI $=1.02-$ 2.89).
Association of the combined genotypes of rs11549467 and rs2057482 polymorphisms with PCa risk

We then performed the linkage disequilibrium analysis between the three SNPs; however, we failed to find the existence of linkage disequilibrium $\left(D^{\prime}=0.406, r^{2}=0.0\right.$ for $\mathrm{rs} 11549465$ and rs11549467; $D^{\prime}=0.537, r^{2}=0.039$ for $r 11549465$ and $\mathrm{rs} 2057482 ; D^{\prime}=0.57$, $r^{2}=0.002$ for rs11549467 and rs2057482). So the haplotype effect was not conducted in the further analysis. Although the difference in allele distribution of rs11549467 and rs2057482 polymorphisms among cases and controls did not reach statistical significance, the rs11549467A and rs2057482C allele appeared to be risk alleles for PCa. So we combined the two SNPs to evaluate their joint effect on risk of PCa. As shown in Table 4, individuals with more risk alleles were associated with a significantly increased risk for PCa in a doseresponse manner compared with individuals with none risk alleles $\left(P_{\text {trend }}=0.023\right)$. We then categorized all alleles of each of the two SNPs into two different groups according to the number of risk alleles (0-2 and 3-4). We found that individuals with three or four risk alleles had a significantly increased PCa risk compared to those with less than two risk alleles (adjusted $\mathrm{OR}=2.10 ; 95 \% \mathrm{CI}=1.23-3.75$ ).

\section{Association between HIF1A polymorphisms and} clinicopathological characteristics of PCa patients

We then investigated the association of the three HIF1A polymorphisms and clinicopathological characteristics of PCa patients. As shown in Table 5, the rs11549467 GA+AA were significantly more frequent in patients with Gleason score $>7$ (adjusted $\mathrm{OR}=2.14$; $95 \% \mathrm{CI}=1.22-3.75)$. There were no other significant associations between the evaluated genotypes and clinical stage, Gleason score or prostate-specific antigen (PSA) levels of PCa patients.

Table 2 Genotype and allele frequencies of the HIF1A polymorphisms among the PCa cases and controls

\begin{tabular}{|c|c|c|c|c|c|c|}
\hline \multirow{2}{*}{ Polymorphisms } & \multicolumn{2}{|c|}{ Cases $(\mathrm{n}=662)$} & \multicolumn{2}{|c|}{ Controls $(n=716)$} & \multirow{2}{*}{$\mathrm{P}^{a}$} & \multirow{2}{*}{ Adjusted OR $(95 \% \mathrm{Cl})^{b}$} \\
\hline & $n$ & $\%$ & $\mathrm{n}$ & $\%$ & & \\
\hline \multicolumn{7}{|c|}{ HIF1A rs11549465 } \\
\hline $\mathrm{CC}$ & 612 & 92.5 & 659 & 92.0 & 0.302 & 1.00 (reference) \\
\hline $\mathrm{CT}$ & 48 & 7.2 & 57 & 8.0 & & $0.91(0.61-1.37)$ \\
\hline TT & 2 & 0.3 & 0 & 0.0 & & - \\
\hline $\mathrm{CT}+\mathrm{TT}$ & 50 & 7.5 & 57 & 8.0 & 0.708 & $0.95(0.64-1.42)$ \\
\hline C & 1272 & 96.1 & 1375 & 96.0 & 0.943 & \\
\hline $\mathrm{T}$ & 52 & 3.9 & 57 & 4.0 & & \\
\hline$P_{\text {trend }}$ & & & & & 0.943 & \\
\hline \multicolumn{7}{|c|}{ HIF1A rs11549467 } \\
\hline GG & 614 & 92.8 & 685 & 95.7 & 0.048 & 1.00 (reference) \\
\hline $\mathrm{GA}$ & 47 & 7.0 & 31 & 4.3 & & $1.66(1.04-2.67)$ \\
\hline $\mathrm{AA}$ & 1 & 0.2 & 0 & 0 & & - \\
\hline $\mathrm{GA}+\mathrm{AA}$ & 48 & 7.2 & 31 & 4.3 & 0.020 & $1.70(1.06-2.72)$ \\
\hline G & 1275 & 96.3 & 1401 & 97.8 & 0.281 & \\
\hline A & 49 & 3.7 & 31 & 2.2 & & \\
\hline$P_{\text {trend }}$ & & & & & 0.016 & \\
\hline \multicolumn{7}{|c|}{ HIF1A rs2057482 } \\
\hline $\mathrm{CC}$ & 418 & 63.1 & 428 & 59.8 & 0.258 & 1.00 (reference) \\
\hline CT & 212 & 32.0 & 241 & 33.7 & & $1.31(0.80-2.15)$ \\
\hline $\mathrm{TT}$ & 32 & 4.8 & 47 & 6.6 & & $1.44(0.90-2.32)$ \\
\hline $\mathrm{CT}+\mathrm{TT}$ & 244 & 36.9 & 288 & 40.2 & 0.200 & $1.40(0.87-2.31)$ \\
\hline C & 1048 & 79.2 & 1097 & 76.6 & 0.108 & \\
\hline $\mathrm{T}$ & 276 & 20.8 & 335 & 23.4 & & \\
\hline$P_{\text {trend }}$ & & & & & 0.116 & \\
\hline
\end{tabular}

Abbreviations: $\mathrm{Cl}$, confidence interval; $\mathrm{OR}$, odds ratio; $\mathrm{PCa}$, prostate cancer.

${ }^{a}$ Two-sided $\chi^{2}$ test for either genotype distributions or allele frequencies between the cases and controls.

${ }^{\mathrm{b}}$ Adjusted for age, smoking, drinking status and family history of cancer in logistic regression model. 
Table 3 Stratification analyses between HIF1A rs11549467 polymorphisms and risk of PCa

\begin{tabular}{|c|c|c|c|c|c|c|c|}
\hline \multirow{3}{*}{ Variables } & \multirow{3}{*}{ Cases/controls } & \multicolumn{4}{|c|}{ Genotypes (cases/controls) } & \multirow{3}{*}{$\mathrm{P}^{a}$} & \multirow{3}{*}{$\begin{array}{l}\text { Adjusted } O R(95 \% C l)^{b} \\
G A+A A \text { vs. } G G\end{array}$} \\
\hline & & \multicolumn{2}{|c|}{$G G$} & \multicolumn{2}{|c|}{$G A+A A$} & & \\
\hline & & $\mathrm{n}$ & $\%$ & $\mathrm{n}$ & $\%$ & & \\
\hline Total & $662 / 716$ & $614 / 685$ & $92.8 / 95.7$ & $48 / 31$ & $7.2 / 4.3$ & 0.020 & $1.70(1.06-2.72)$ \\
\hline \multicolumn{8}{|l|}{ Age (year) } \\
\hline$\leqslant 71$ & $308 / 360$ & $288 / 344$ & $93.5 / 95.6$ & $20 / 16$ & $6.5 / 4.4$ & 0.242 & $1.41(0.71-2.81)$ \\
\hline$>71$ & $354 / 356$ & $328 / 341$ & $92.1 / 95.8$ & $28 / 15$ & $7.9 / 4.2$ & 0.039 & $2.01(1.05-3.86)$ \\
\hline \multicolumn{8}{|c|}{ Smoking status } \\
\hline Never & $277 / 350$ & 258/333 & 93.1/95.1 & $19 / 17$ & $6.9 / 4.9$ & 0.285 & $1.37(0.69-2.71)$ \\
\hline Ever & $385 / 366$ & $356 / 352$ & $92.5 / 96.2$ & $29 / 14$ & $7.5 / 3.8$ & 0.029 & $2.06(1.07-3.99)$ \\
\hline \multicolumn{8}{|c|}{ Drinking status } \\
\hline Never & $468 / 541$ & $434 / 522$ & $92.7 / 96.5$ & $34 / 17$ & $7.3 / 3.5$ & 0.008 & $2.16(1.20-3.86)$ \\
\hline Ever & $194 / 175$ & $180 / 163$ & 92.8/93.1 & $14 / 12$ & $7.2 / 6.9$ & 0.893 & $1.07(0.48-2.40)$ \\
\hline \multicolumn{8}{|c|}{ Family history of cancer } \\
\hline No & $493 / 607$ & $457 / 581$ & $92.7 / 95.7$ & $36 / 26$ & $7.3 / 4.3$ & 0.031 & $1.71(1.02-2.89)$ \\
\hline Yes & $169 / 109$ & $157 / 104$ & $92.9 / 95.4$ & $12 / 5$ & $7.1 / 4.6$ & 0.393 & $1.58(0.54-4.63)$ \\
\hline
\end{tabular}

Abbreviations: $\mathrm{Cl}$, confidence interval; OR, odds ratio; $\mathrm{PCa}$, prostate cancer.

${ }^{a}$ Two-sided $\chi^{2}$ test for the distributions between the cases and controls.

${ }^{\mathrm{b}}$ Adjusted for age, smoking, drinking status and family history of cancer in logistic regression model.

\section{DISCUSSION}

In this study, we evaluated the effects of HIF1A polymorphisms on the susceptibility and clinicopathological development of PCa in a Chinese population. Our results suggested that genotype variation of rs11549467 polymorphism was associated with increased risk for $\mathrm{PCa}$, especially in the patients with AA or GA genotypes, and individuals with variant genotype were associated with high grade disease (Gleason score $>7$ ). We could not find any significant difference in the rs11549465 and rs2057482 genotype frequency between the PCa patients and controls. Although rs11549465 and rs2057482 genotypes had no statistically significantly increased risk of PCa, we evaluated rs2057482 and rs11549467 together and found that individuals with three or four risk alleles (i.e., rs11549467A and rs2057482T) had a 2.10-times increased risk of PCa.

Angiogenesis plays a pivotal role in the growth, invasion and metastasis of many kinds of solid tumor. ${ }^{29} \mathrm{~A}$ key regulator of angiogenesis in response to hypoxia lesion is HIF- $1 \alpha$, whose enhanced expression was demonstrated as an early event in prostate carcinogenesis both in animal model studies ${ }^{30}$ and in human prostate cancer specimens. ${ }^{31}$ Despite evident associations between HIF1A polymorphisms and risk for various kinds of cancers, ${ }^{14}$ the role of these SNPs in prostate carcinogenesis appears complex. Chau et al. ${ }^{25}$ reported that rs11549465 conferred susceptibility to androgen-independent PCa in 196 patients. In support of their results, Orr-Urtreger et al. ${ }^{32}$ also suggested that homozygous variation of rs11549465 conferred significant susceptibility to PCa. Recently, Foley et al. ${ }^{23}$ reported that a heterozygous genotype of rs11549465 was an increased risk factor for clinically localized PCa, but not with elevated expression of hypoxic biomarkers. However, in a large case-control study of 1072 PCa patients and 1271 controls, Li et al. ${ }^{24}$ demonstrated that neither the rs11549465 nor the rs11549467 polymorphism was associated with risk of PCa. In agreement with Li et al., we observed no associations between rs11549465 and PCa risk. In addition, we also found no correlation between the frequency of rs11549465 genotype and clinical or pathological characteristics of the patients, including clinical stage, Gleason score and PSA levels. However, we identified a variant genotype of rs11549467 as

Table 4 Frequency distributions of the combined genotypes of rs $11549467 \mathrm{G}>\mathrm{A}$ and rs2057482 C $>$ T polymorphisms among the cases and controls, and their correlation to risk of $\mathrm{PCa}$

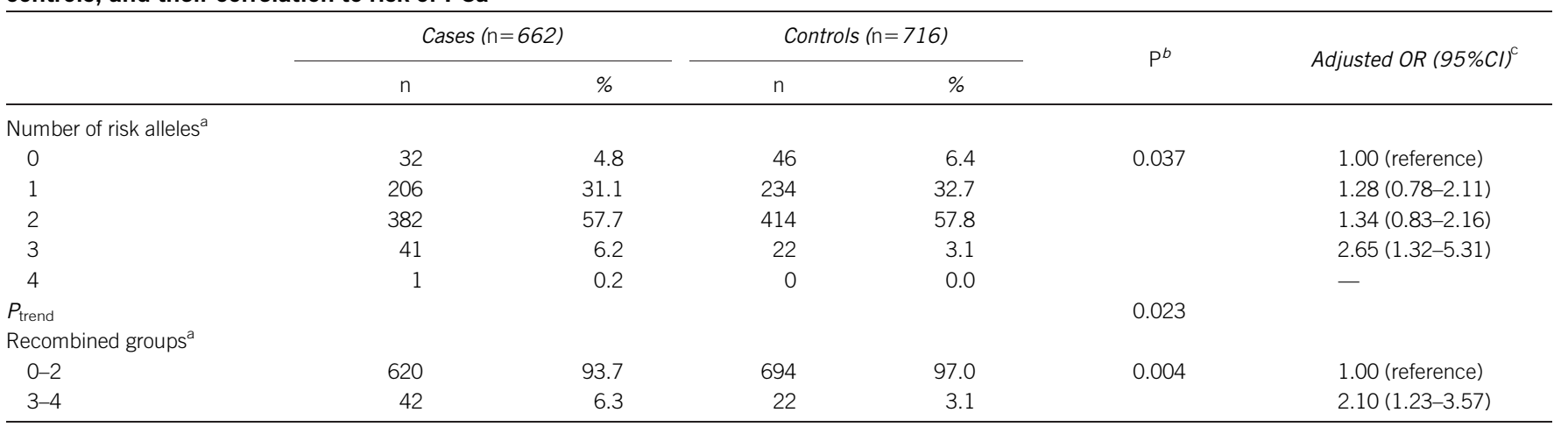

Abbreviations: $\mathrm{Cl}$, confidence interval; OR, odds ratio; $\mathrm{PCa}$, prostate cancer.

${ }^{a}$ The $0-4$ represents the numbers of risk alleles within the combined genotypes; the risk alleles used for the calculation were the rs $11549467 \mathrm{~A}$ and rs $2057482 \mathrm{C}$ alleles.

${ }^{\mathrm{b}}$ Two-sided $\chi^{2}$ test for the distributions between the cases and controls.

${ }^{c}$ Adjusted for age, smoking, drinking status and family history of cancer in logistic regression model. 
Table 5 HIF1A polymorphisms and clinicopathological characteristics in patients with PCa

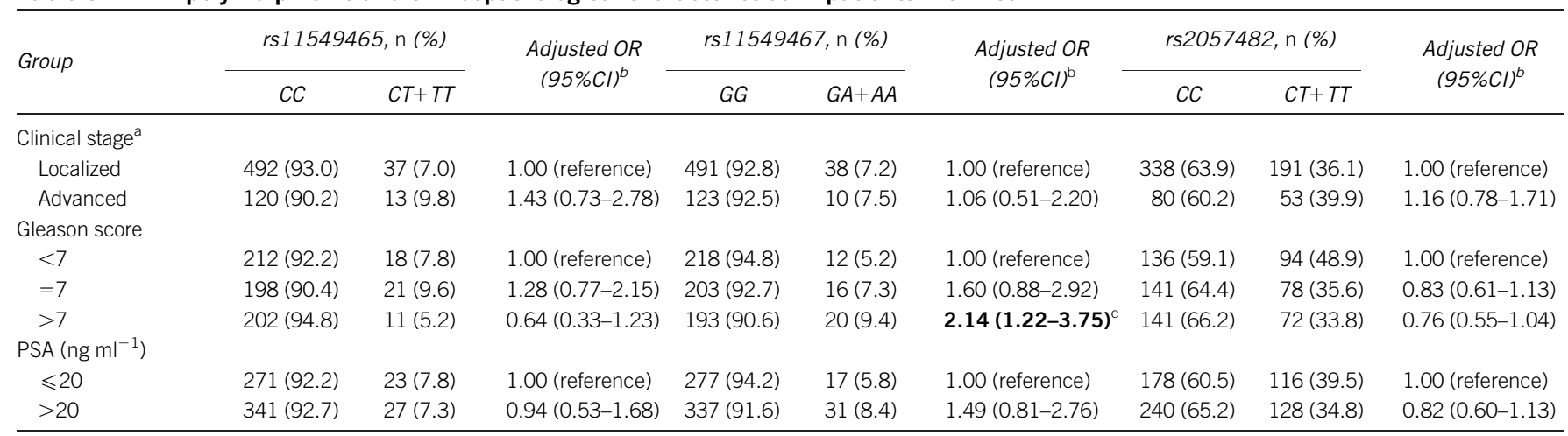

Abbreviations: $\mathrm{Cl}$, confidence interval; OR, odds ratio; $\mathrm{PCa}$, prostate cancer; PSA, prostate-specific antigen.

a Localized: $T_{1-2} N_{0} M_{0}$; advanced: $T_{3-4} N_{x} M_{x}$ or $T_{x} N_{1} M_{x}$ or $T_{x} N_{x} M_{1}$. Clinical staging according to the international tumor-node metastasis system for PCa.

${ }^{\mathrm{b}}$ Adjusted for age, smoking, drinking status and family history of cancer in logistic regression model.

${ }^{\mathrm{c}}$ Bold-faced values indicate significant difference at the $5 \%$ level $(P=0.032)$.

a risk factor for PCa in the Chinese population and the variant genotype positively correlated with the development of high-grade tumor. The results were consistent with previous studies in oral cancer ${ }^{18}$ and hepatocellular carcinoma, ${ }^{22}$ which also suggested that a polymorphic variant of rs11549467 was associated with increased cancer risk. It has been suggested that both the rs 11549465 and rs11549467 polymorphic variants of HIF1A showed a significantly higher transcriptional activity than that of the wild type under both normoxic and hypoxic conditions. ${ }^{13}$ Additionally, in most cancers, high HIF- $1 \alpha$ levels have been associated with tumor progression and poor prognosis. ${ }^{33,34} \mathrm{We}$ therefore hypothesized that the rs1 1549467 variant genotype of HIF1A might contribute to the development and progression of PCa through increasing HIF- $1 \alpha$ protein levels and HIF- $1 \alpha$ downstream effects. Despite enhanced transcription activity of HIF1A rs1 1549465 variants, rs11549465 appeared to have no effect on the development of PCa, which might suggest that a distinct mechanism underlying the regulation of HIF- $1 \alpha$ and its target genes through these two SNPs may exist. These discrepancies between our current study and previous studies regarding PCa risk might reflect differences in ethnic population as incidence of prostate cancer varies widely between ethnic populations and countries with lowest rates in Asia, especially in Chinese population.

In addition, our results indicated that the risk associated with the rs11549467 polymorphism was more pronounced in older subjects ( $>71$ years), but not in younger subjects ( $\leqslant 71$ years), suggesting that interaction between $H I F 1 A$ genetic variations and age may contribute to the incidence of PCa. We also observed that the effect of rs 11549467 polymorphism on risk of PCa was more predominate among smokers. Although smoking is not an established risk factor for PCa, it was suggested that nicotine which is the major active and addictive component of tobacco can induce proliferation and angiogenesis in a variety of human cancer cell lines as well as in murine models. ${ }^{35} \mathrm{We}$ speculated that the interaction effect between rs11549467 polymorphism and smoking may contribute to the occurrence of $\mathrm{PCa}$, as smoking donates its promotion effect of angiogenesis, consequently increasing the risk for PCa. However, this increased risk associated with rs11549467 polymorphism was more pronounced in non-drinkers instead of in ever drinkers, suggesting that the genetic effect might be overwhelmed by the environment effect. Similar association was observed in the stratified analysis of the family history of cancer, in which the polymorphism effect might be overwhelmed by the effect of other inherit genetic factors, thus increased risk associated with rs 11549467 polymorphism was only present in the subgroup of patients without a family history of cancers.

We also assessed the association of another SNP (rs2057482) located in $3^{\prime}$ UTR region of HIF1A and risk for PCa, which has not been investigated by previous studies regarding carcinogenesis. Although the frequency of rs2057482C allele in PCa patients was more than that in controls, the difference did not reach statistical significance. Similar frequency distribution of rs11549467A allele has also been observed. However, rs2057482 appeared to interact with rs11549467; indeed, we found that the combined risk alleles of both SNPs were significantly associated with an increased risk for PCa in a dose-response manner. The joint effect of both SNP on the risk of PCa might suggest that interaction between these two SNP may be involved in PCa carcinogenesis. It was suggested that microRNAs could act as posttranscriptional regulators of gene expression by either mRNA degradation or translational repression. ${ }^{36}$ Considering the position of 3' UTR where rs2057482 is located, it is biologically plausible that such a variation at this position may alter HIF1A expression through influencing mRNA stability, and subsequently contribute to the risk of PCa. However, further functional study is needed to clarify the potential role of rs2057482 in regulating the expression of HIF1A.

Our results indicate that rs 11549467 gene polymorphism of HIF1A is a crucial factor for the susceptibility and progression of PCa. When interpreting our results, several limitations should be considered. First, because our case-control study was hospital-based, we could not rule out the possibility of selection bias of subjects that may have been associated with a particular genotype. However, the genotype distributions of HIF1A polymorphisms in our study population were similar to the distributions reported in HapMap database, indicating that the selection bias in terms of genotype distribution would not be substantial. Second, considering the low frequency of variant alleles, the sample size of present study may be limited. For instance, when we conducted multiple comparisons to access the association, none of these SNPs were significant. Third, body mass index, diabetes status and dietary factors may also influence the risk of PCa; however, lack of the information limited our study to further investigate the interaction between SNPs and these factors. Therefore, large population-based prospective studies with detail information on these factors are warranted to further elucidate the impact of HIF1A polymorphism on PCa susceptibility. 


\section{AUTHOR CONTRIBUTIONS}

PL, QC and PFS completed the data analyses and performed the majority of the experimental work; HZC, HZ and JWC completed the samples collection and DNA extraction; $\mathrm{ZDZ}$ assisted with date analysis; XBJ and CJY assisted with experimental design and research supervision; all authors participated in drafting of the article and approved the final article.

\section{COMPETING FINANCIAL INTERESTS}

All authors declare that there are no competing financial interests.

\section{ACKNOWLEDGMENTS}

This work was supported by the Program for Development of Innovative Research Team in the First Affiliated Hospital of Nanjing Medical University, Provincial Initiative Program for Excellency Disciplines of Jiangsu Province, by the National Natural Science Foundation of China (grant Nos. 81171963 and 81102089 ) and the Natural Science Foundation of Jiangsu Province (grant Nos. BK2008473 and BK2011773).

1 Jemal A, Siegel R, Ward E, Hao Y, Xu J. Cancer statistics, 2009. CA Cancer J Clin 2009; 59: 225-49.

2 McCracken M, Olsen M, Chen MS Jr, Jemal A, Thun M et al. Cancer incidence, mortality, and associated risk factors among Asian Americans of Chinese, Filipino, Vietnamese, Korean, and Japanese ethnicities. CA Cancer J Clin 2007; 57: 190-205.

3 Dianat SS, Margreiter M, Eckersberger E, Finkelstein J, Kuehas F et al. Gene polymorphisms and prostate cancer: the evidence. BJU Int 2009; 104: 1560-72.

4 Jacobs EJ, Hsing AW, Bain EB, Stevens VL, Wang Y et al. Polymorphisms in angiogenesis-related genes and prostate cancer. Cancer Epidemiol Biomarkers Prev 2008; 17: 972-7.

5 Sfar S, Saad H, Mosbah F, Chouchane L. Synergistic effect and VEGF/HSP70-hom haplotype analysis: relationship to prostate cancer risk and clinical outcome. Hum Immunol 2010; 71: 377-82.

6 VanCleave TT, Moore JH, Benford ML, Brock GN, Kalbfleisch T et al. Interaction among variant vascular endothelial growth factor (VEGF) and its receptor in relation to prostate cancer risk. Prostate 2010; 70: 341-52.

7 Zhong H, de Marzo AM, Laughner E, Lim M, Hilton DA et al. Overexpression of hypoxiainducible factor 1 alpha in common human cancers and their metastases. Cancer Res 1999; 59: 5830-5.

8 Charlesworth PJ, Harris AL. Mechanisms of disease: angiogenesis in urologic malignancies. Nat Clin Pract Urol 2006; 3: 157-69.

9 Semenza GL. Targeting HIF-1 for cancer therapy. Nat Rev Cancer 2003; 3: 721-32.

10 Baldewijns MM, van Vlodrop IJ, Vermeulen PB, Soetekouw PM, van Engeland M. VHL and HIF signalling in renal cell carcinogenesis. J Pathol 2010; 221: 125-38.

11 Kimbro KS, Simons JW. Hypoxia-inducible factor-1 in human breast and prostate cancer. Endocr Relat Cancer 2006; 13: 739-49.

12 Clifford SC, Astuti D, Hooper L, Maxwell PH, Ratcliffe PJ. The pVHL-associated SCF ubiquitin ligase complex: molecular genetic analysis of elongin $\mathrm{B}$ and $\mathrm{C}, \mathrm{Rbx} 1$ and HIF-1alpha in renal cell carcinoma. Oncogene 2001; 20: 5067-74.

13 Tanimoto K, Yoshiga K, Eguchi H, Kaneyasu M, Ukon K et al. Hypoxia-inducible factor-1alpha polymorphisms associated with enhanced transactivation capacity, implying clinical significance. Carcinogenesis 2003; 24: 1779-83.

14 Zhao T, Lv J, Zhao J, Nzekebaloudou M. Hypoxia-inducible factor-1alpha gene polymorphisms and cancer risk: a meta-analysis. J Exp Clin Cancer Res 2009; 28: 159.

15 Naidu R, Har YC, Taib NA. Associations between hypoxia-inducible factor-1alpha (HIF-1alpha) gene polymorphisms and risk of developing breast cancer. Neoplasma 2009; 56: 441-7.
16 Apaydin I, Konac E, Onen HI, Akbaba M, Tekin E. Single nucleotide polymorphisms in the hypoxia-inducible factor-1alpha (HIF-1alpha) gene in human sporadic breast cancer. Arch Med Res 2008; 39: 338-45.

17 Shieh TM, Chang KW, Tu HF, Shih YH, Ko SY et al. Association between the polymorphisms in exon 12 of hypoxia-inducible factor-1alpha and the clinicopathological features of oral squamous cell carcinoma. Oral Oncol 2010; 46 e47-53.

18 Chen MK, Chiou HL, Su SC, Chung TT, Tseng HC et al. The association between hypoxia inducible factor-1alpha gene polymorphisms and increased susceptibility to oral cancer. Oral Oncol 2009; 45: e222-6.

19 Ollerenshaw M, Page T, Hammonds J, Demaine A. Polymorphisms in the hypoxia inducible factor-1alpha gene (HIF1A) are associated with the renal cell carcinoma phenotype. Cancer Genet Cytogenet 2004; 153: 122-6.

20 Szkandera J, Knechtel G, Stotz M, Hofmann G, Langsenlehner U et al. Association of hypoxia-inducible factor 1 -alpha gene polymorphisms and colorectal cancer prognosis. Anticancer Res 2010; 30: 2393-7.

21 Knechtel G, Szkandera J, Stotz M, Hofmann G, Langsenlehner U et al. Single nucleotide polymorphisms in the hypoxia-inducible factor- 1 gene and colorectal cancer risk. Mol Carcinog 2010; 49: 805-9.

22 Hsiao PC, Chen MK, Su SC, Ueng KC, Chen YC et al. Hypoxia inducible factor-1alpha gene polymorphism G1790A and its interaction with tobacco and alcohol consumptions increase susceptibility to hepatocellular carcinoma. J Surg Oncol 2010; 102: 163-9.

23 Foley R, Marignol L, Thomas AZ, Cullen IM, Perry AS et al. The HIF-1alpha C1772T polymorphism may be associated with susceptibility to clinically localised prostate cancer but not with elevated expression of hypoxic biomarkers. Cancer Biol Ther 2009; 8: 118-24.

24 Li H, Bubley GJ, Balk SP, Gaziano JM, Pollak M et al. Hypoxia-inducible factor-1alpha (HIF-1alpha) gene polymorphisms, circulating insulin-like growth factor binding protein (IGFBP)-3 levels and prostate cancer. Prostate 2007; 67: 1354-61.

25 Chau CH, Permenter MG, Steinberg SM, Retter AS, Dahut WL et al. Polymorphism in the hypoxia-inducible factor 1 alpha gene may confer susceptibility to androgenindependent prostate cancer. Cancer Biol Ther 2005; 4: 1222-5.

26 Konac E, Dogan I, Onen HI, Yurdakul AS, Ozturk C et al. Genetic variations in the hypoxia-inducible factor-1alpha gene and lung cancer. Exp Biol Med (Maywood) 2009; 234: 1109-16.

27 Epstein JI, Allsbrook WC Jr, Amin MB, Egevad LL. The 2005 International Society of Urological Pathology (ISUP) Consensus Conference on Gleason Grading of Prostatic Carcinoma. Am J Surg Pathol 2005; 29: 1228-42.

28 Dupont WD, Plummer WD Jr. Power and sample size calculations. A review and computer program. Control Clin Trials 1990; 11: 116-28.

29 Pouyssegur J, Dayan F, Mazure NM. Hypoxia signalling in cancer and approaches to enforce tumour regression. Nature 2006; 441: 437-43.

30 Huss WJ, Hanrahan CF, Barrios RJ, Simons JW, Greenberg NM. Angiogenesis and prostate cancer: identification of a molecular progression switch. Cancer Res 2001; 61: $2736-43$.

31 Zhong H, Semenza GL, Simons JW, de Marzo AM. Up-regulation of hypoxia-inducible factor 1 alpha is an early event in prostate carcinogenesis. Cancer Detect Prev 2004; 28: 88-93.

32 Orr-Urtreger A, Bar-Shira A, Matzkin H, Mabjeesh NJ. The homozygous P582S mutation in the oxygen-dependent degradation domain of HIF-1 alpha is associated with increased risk for prostate cancer. Prostate 2007; 67: 8-13.

33 Birner P, Schindl M, Obermair A, Plank C, Breitenecker G. Overexpression of hypoxiainducible factor 1 alpha is a marker for an unfavorable prognosis in early-stage invasive cervical cancer. Cancer Res 2000; 60: 4693-6.

34 Batmunkh E, Shimada M, Morine Y, Imura S, Kanemura H et al. Expression of hypoxiainducible factor-1 alpha (HIF-1alpha) in patients with the gallbladder carcinoma. Int J Clin Oncol 2010; 15: 59-64.

35 Egleton RD, Brown KC, Dasgupta P. Angiogenic activity of nicotinic acetylcholine receptors: implications in tobacco-related vascular diseases. Pharmacol Ther 2009; 121: 205-23.

36 Filipowicz W, Bhattacharyya SN, Sonenberg N. Mechanisms of post-transcriptiona regulation by microRNAs: are the answers in sight? Nat Rev Genet 2008; 9: 102-14. 